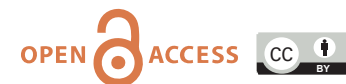

doi: 10.31729/jnma.5606

\title{
Multiple Cavernous Haemangioma of Orbit and Cranium: A Case Report
}

\author{
Purnima Rajkarnikar Sthapit, ${ }^{1}$ Gita Sayami, ${ }^{2}$ Rohit Saiju' \\ 'Department of Oculoplasty and Ocular Oncology, Tilganga Institute of Ophthalmology, Kathmandu, Nepal, \\ ${ }^{2}$ Department of Pathology, HAMS Hospital, Kathmandu, Nepal.
}

\section{ABSTRACT}

A 32-year-old male presented with painless proptosis and diminution of vision in left eye. Imaging shows multiple well-defined masses, suggestive of cavernous haemangioma, in orbit and cranium with adjoining bones being thickened with cystic spaces. Histopathology proved the diagnosis. Cavernous haemangioma usually presents as a solitary intraconal and sometimes extraconal mass with vision usually preserved unless it extends to the apical portion. Here we report a rare case of multiple simultaneous locations of cavernous haemangiomas in orbit and cranium with significant diminution of vision.

Keywords: cavernous haemangioma; cranial haemangioma; multiple haemangiomas; orbital haemangioma.

\section{INTRODUCTION}

Cavernous hemangioma is the most typical orbital tumor in adults in their third or fourth decade. It usually presents as a solitary tumor rarely affecting the vision. Treatment is straightforward with complete excision by orbitotomy surgery. However, multiple cavernous hemangiomas of orbit and cranium are rare but possible presentations, making it a diagnostic dilemma and management difficulty.

\section{CASE REPORT}

A 32-year-old male presented with left sided gradual onset painless progressive forward protrusion of eyeball associated with gradual onset diminution of vision in same eye since four years.

On examination, the best-corrected visual acuity in the right eye (RE) was 20/20, while in the left eye (LE) was $20 / 400$. Anterior segment and fundus examination of RE was within normal limits.

Examination of LE shows the fullness of the upper and lower lid with prominent eccentric proptosis. The eyeball was protruded four $\mathrm{mm}$ axial and three $\mathrm{mm}$ downward displaced, as shown in Figure 1. No increase of proptosis was noted on the Valsalva maneuver. Retropulsion of the globe was negative. However, extraocular movements were normal. LE also had a relative afferent pupillary defect and temporal disc pallor. The patient did not give any history of neurological illness like seizures.
Figures 2,3 and 4 show CT scan brain and orbit with multiple (at least 16) well-defined round to oval, intra, and extraconal masses in the left orbit- size ranged from 0.4 to $2.3 \mathrm{~cm}$ in largest diameter. Similar lesions were seen in tentorium, falx cerebri, and scalp as well. The left zygomatic, frontal, and parietal bones were found to be thickened with cystic spaces. He was posted for lateral orbitotomy for excision biopsy of the lesions with the provisional diagnosis of multiple cavernous hemangiomas of orbit.

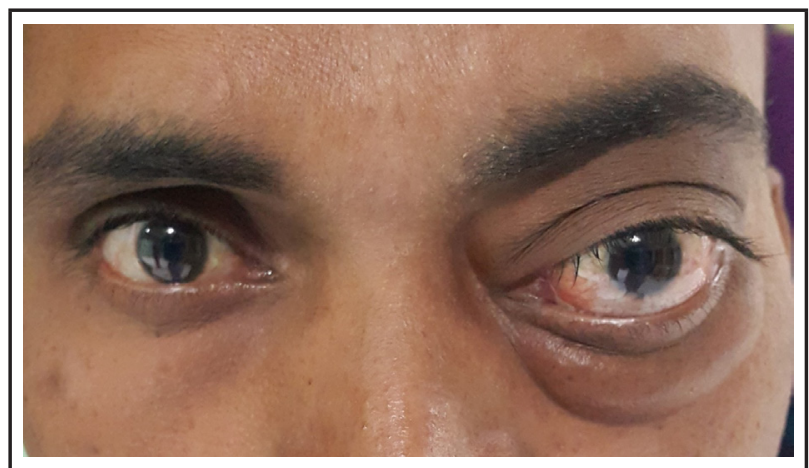

Figure 1. Patient presenting with proptosis and edema of eyelids and conjunctiva of left eye.

Intraoperatively, we found multiple solid, solitary dark red colored lesions (Figure 5), which were removed

Correspondence: Dr. Purnima Rajkarnikar Sthapit, Department of Oculoplasty and Ocular Oncology, Tilganga Institute of Ophthalmology, Kathmandu, Nepal. Email: purnimark@gmail.com, Phone: +977-9813254962. 
as much as possible. The histopathology slide in figure 6 shows cystic thin-walled vascular channels lined by bland endothelial cells confirming Cavernous haemangioma's diagnosis. Vision in LE remained 20/400 postoperatively. Neurosurgical consultation confirmed the cranial lesions as the same. Given no neurological symptoms, they advised no intervention but to wait and watch.

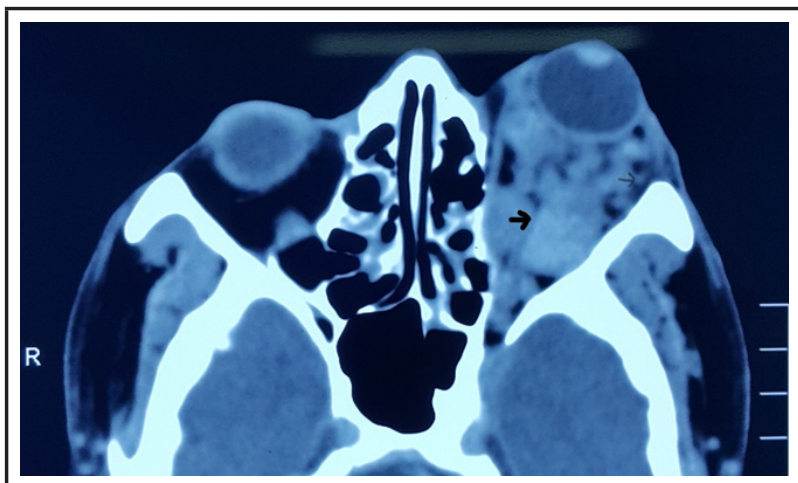

Figure 2. Plain CT scan orbit. Axial view showing multiple (at least 16) well defined round to oval, intra and extraconal masses in the left orbit- size ranged from 0.4 (small arrow) to $2.3 \mathrm{~cm}$ (big arrow) in largest diameter.

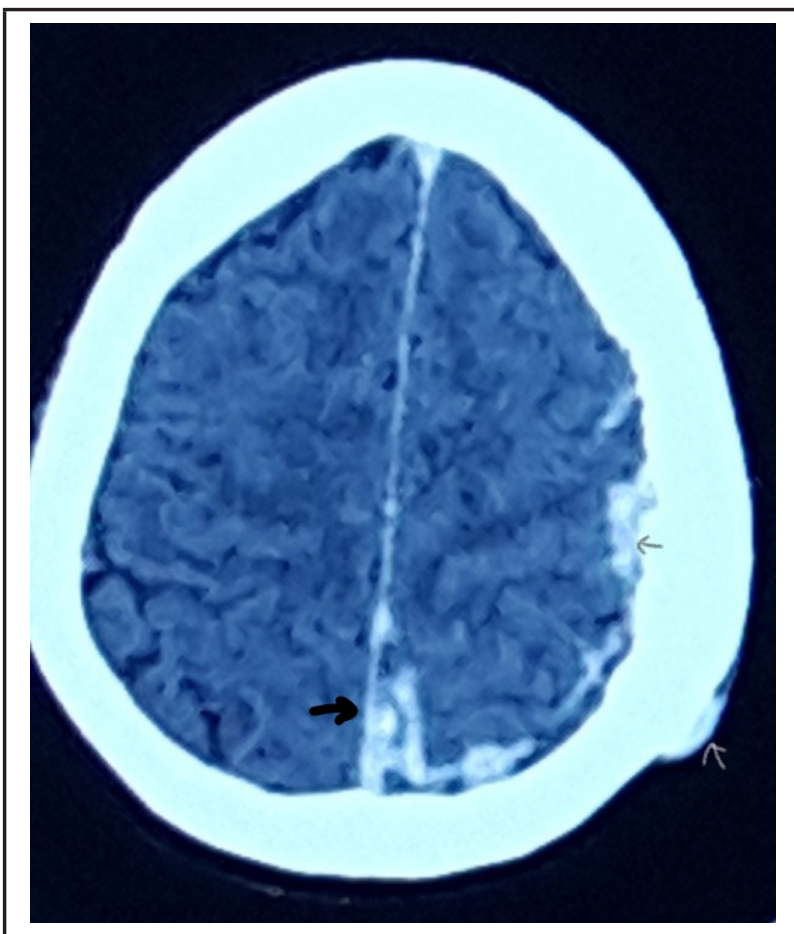

Figure 3. Plain CT scan brain axial view showing similar lesions in tentorium, falx (thick black arrow), dural surface (thin black arrow) and scalp (white arrow) of same side.

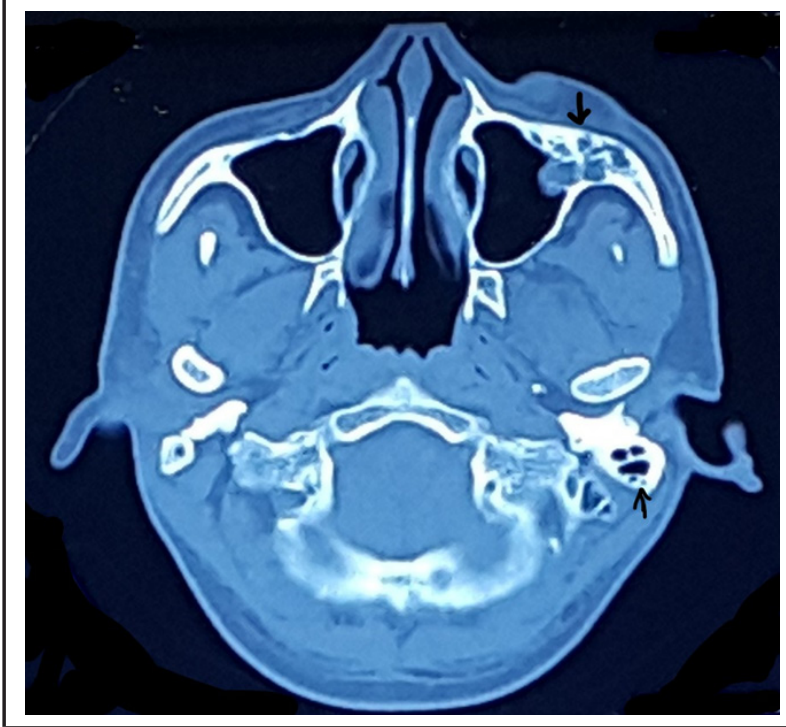

Figure 4. CT scan axial view bone window view showing thickened left parietal (thin arrow), maxillary and zygomatic bone (thick arrow) of left orbit with cystic spaces giving "honeycomb" appearance.

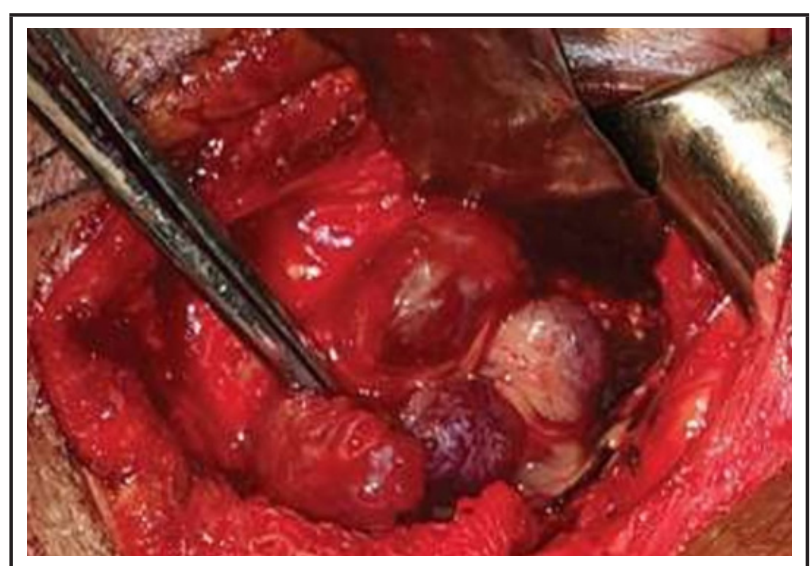

Figure 5. Intraoperative finding- multiple solid, solitary, dark red coloured lesions.

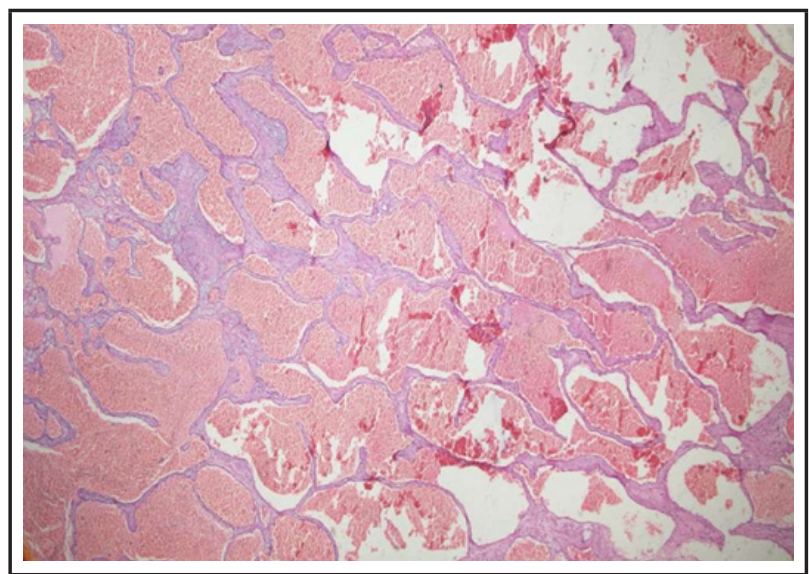

Figure 6. Hematoxylin and Eosin stain showing a thin walled vascular channels. 


\section{DISCUSSION}

Cavernous hemangioma is the most common benign vascular tumor of the orbit in adults. ${ }^{1}$ Alan Mc Nab et al. states that it usually presents as a solitary intraconal lesion in $87 \%$ and sometimes as extraconal mass. In their study in 104 patients, all had single cavernous hemangioma in various parts of the orbit. ${ }^{2}$ A study also shows that $33 \%$ of patients have optic nerve dysfunction as well, ${ }^{3}$ which is likely in our case as well in view of reduced vision, RAPD, and disc pallor. Multiple cerebral cavernous hemangiomas have been reported in a child presenting with seizures, with most lesions located in supratentorial, frontal, and temporal lobes. These remain asymptomatic until intracranial hemorrhage occurs. ${ }^{4}$ Therefore, a close follow-up is required in a case like ours where intracranial hemorrhage may occur.

Multiple intraosseous cavernous haemangiomas similar to our patient is also reported by other studies in various locations like skull, spine, and inferior orbital rim. ${ }^{5,6,7,8}$ However, ours is the only case report with simultaneous presentation of multiple and multifocal presentations of cavernous haemangioma of orbit and cranium. According to a report by Brunereau $L$ et al., our patient may have had the hereditary type of this disease given the tendency to form multiple lesions is seen in the hereditary rather than the sporadic type, ${ }^{8}$ however he had no family history. Complete surgical excision is a preferred treatment. Gamma knife radiotherapy and stereotactic radiation have also been tried for surgically challenging apical cases impeaching optic nerve with $76 \%$ reduction in the tumor volume. ${ }^{9}$ We would like to conclude by saying that cavernous haemangioma can rarely present multiple lesions in multiple sites in and outside the orbit.

Consent: JNMA Case Report Consent Form was signed by the patient and the original article is attached to the patient's chart.

\section{Conflict of Interest: None.}

\section{REFERENCES}

1. Honavar SG, Manjandavida FP. Recent Advances in Orbital Tumors--A Review of Publications from 2014-2016. Asia Pac J Ophthalmol (Phila). 2017 Mar-Apr;6(2):153-8. [ [ Full Text | DOI]

2. McNab AA, Selva D, Hardy TG, O'Donnell B. The anatomical location and laterality of orbital cavernous haemangiomas. Orbit. 2014 Oct;33(5):359-62. [PubMed | Full Text | DOI]

3. Rootman DB, Heran MK, Rootman J, White VA, Luemsamran $\mathrm{P}$, Yucel YH. Cavernous venous malformations of the orbit (so-called cavernous haemangioma): a comprehensive evaluation of their clinical, imaging and histologic nature. Br J Ophthalmol. 2014 Jul;98(7):880-8. [uㅏMed | Full Text I DOI]

4. Verma P, Saleem R, Harijan P, Hussain N. Multiple cerebral cavernous haemangiomas in an infant. J Pediatr Neurosci. 2012 Sep;7(3):200-1. [PubMed | Full Text | DOI]

5. Friedrich RE, Grzyska U, Kohlrusch FK, VON Kroge S, Vollkommer T, Luebke AM. Symptomatic Intraosseous Vascular Malformation of Infraorbital Rim: A Case
Report with Literature Survey. Anticancer Res. 2020 Jun;40(6):3333-43. [ubMed | Full Text | DOI]

6. Rumana M, Khursheed N, Farhat M, Othman S, Masood L. Congenital intraosseous cavernous hemangioma of the skull: an unusual case. Pediatr Neurosurg. 2013;49(4):229-31. [PubMed | Full Text | DOI]

7. Hagiwara N, Yahikozawa H. Multiple cavernous haemangioma showing marked calcification on cranial radiography. J Neurol Neurosurg Psychiatry. 2002 Mar;72(3):410. [PubMed | Full Text | DOI]

8. Brunereau L, Labauge $\mathrm{P}$, Tournier-Lasserve E, Laberge S, Levy C, Houtteville JP. Familial form of intracranial cavernous angioma: MR imaging findings in 51 families. French Society of Neurosurgery. Radiology. 2000 Jan;214(1):209-16. [uued | Full Text | DOI]

9. Goh ASC, Kim YD, Woo KI, Lee JI. Benign orbital apex tumors treated with multisession gamma knife radiosurgery. Ophthalmology. 2013 Mar;120(3):635-41. [․ㅏbMed | Full Text $\mid \underline{D O I}]$

\section{The Author(s) 2018}

This work is licensed under a Creative Commons Attribution 4.0 International License. The images or other third party material in this article are included in the article's Creative Commons license, unless indicated otherwise in the credit line; if the material is not included under the Creative Commons license, users will need to obtain permission from the license holder to reproduce the material. To view a copy of this license, visit http://creativecommons.org/licenses/by/4.0/ 